\title{
About the Cover
}

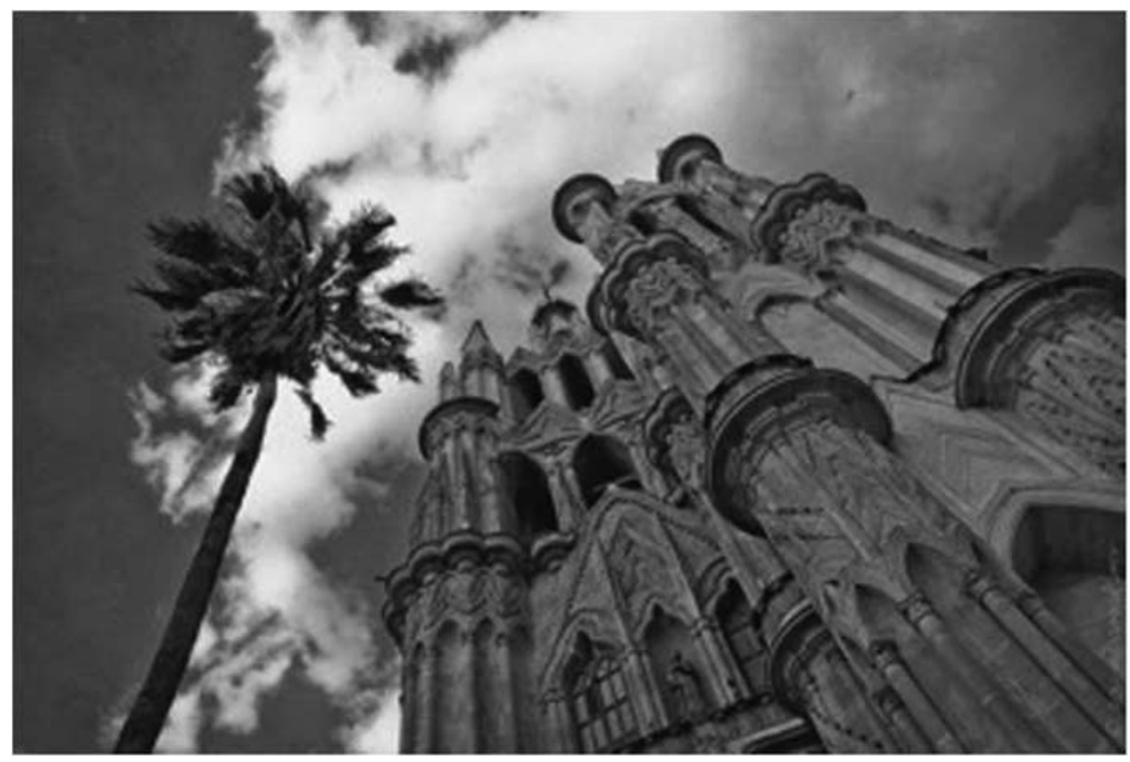

La Parroquia church in San Miguel Allende, Mexico

Cover image $@$ C Edgar Peña (2012); photograph courtesy of the artist.

For further information on Peña's work, see: http://edamak.mx/

postmedieval: a journal of medieval cultural studies (2015) 6, 241-242.

doi:10.1057/pmed.2015.30

The guest editors of Architecture of Colonizers/Architecture of Immigrants, Richard A. Sundt (University of Oregon) and Paul B. Niell (Florida State University), say of its subject - Gothic architecture in Latin America from the sixteenth to the twentieth centuries - that architecture in Latin America is most commonly associated with 'some type of colonial-style building, that is, one that derives its essential inspiration from Renaissance or Baroque traditions.' As a corrective to that common association, this special issue demonstrates how 'this image leaves out a large and important corpus of architecture in the Americas whose sources go back directly to the late Middle Ages.' The essays gathered in this special issue 'provide an introduction to a topic that is virtually unknown,' and they 'identify the circumstances that gave rise to the Gothic style in the colonial period, and subsequently the Gothic Revival in the nineteenth century.'

Neo-Gothic buildings can be found throughout Mexico, Central America and South America; churches are most prominent, but civic structures, schools, 
residences and monuments embody the Gothic Revival as well. This revival was part of the European project of colonization, which in Latin America was influenced, as Niell and Sundt describe the dynamic in the editors' introduction, by 'several factors arising from the colonial situation, chief of which involved matters of location and availability of materials. While some consistency is found with certain strategies of colonization, Spanish claims in the Americas operated in multiple environments, among varying Amerindian populations and with different conquistador histories, all of which impacted stylistic choices in one way or another.' The contributors to the issue investigate the influences of these diverse environments and cultures - local as well as conquistador - on the manifestation of the Gothic in Latin America. Because '[a]s with later styles in colonial Latin America, the dialectic between imperial and local meaning remains opaque with respect to Late Gothic works,' the issue's contributors consider the following questions:

To what extent did a given style signify a proto-national and/or imperial Spanish identity in the early decades of New World colonization? How were such forms understood by European travelers to and from the Americas? To what extent did Gothic forms signify a space outside the monarchical orbit when these were taken up by the mendicants when building their conversion centers? There is still much to learn about how style itself was perceived in this early period. And what about later? Did Gothic forms continue to be relevant and meaningful to Latin American society alongside Renaissance, Baroque and Rococo successions? One thing appears clear, and that is that Late Gothic enjoyed a much different life in the Americas than it did in Europe. 